\title{
Relationship between Injury Risk of Student Occupant and Different Driving Speed of School Bus
}

\author{
Liao $\mathrm{YI}^{1}$, You-Ming TANG ${ }^{*}, 1$, Na LV ${ }^{1}$ and Zhen-Qun FANG ${ }^{2}$
}

${ }^{1}$ Fujian Collaborative Innovation Center for R\&D of Coach and Special Vehicle, Xiamen University of Technology, Xiamen, Fujian, 361024, P. R. China

${ }^{2}$ Xiamen Golden Dragon Auto Seat Co, Ltd, Xiamen, Fujian, 361024, P. R. China

*Corresponding author: tangym1981@163.com

Keywords: School bus, Children occupant, Driving speed, Restraint system.

\begin{abstract}
In order to study the student occupant injury risk of school bus at the driving speed exceeding $30 \mathrm{~km} / \mathrm{h}$, the numerical simulation model of children occupant restraint system of school bus was built using software LS-DYNA 3D. According to the China regulation of GB24406-2012, the model was loaded with four acceleration pluses respectively, so as to compare the Head Injury Criterion (HIC), thorax 3ms acceleration and femur force in different driving speed. The results show that, the student occupant's HIC rises significantly along with the increase of driving speed. The student occupant's thorax injury grows lightly with the increase of driving speed when the speed is lower than $48 \mathrm{~km} / \mathrm{h}$, but grows rapidly once the speed exceeds $48 \mathrm{~km} / \mathrm{h}$. The driving speed range of $30-50 \mathrm{~km} / \mathrm{h}$ is relatively appropriate for the middle school student occupant's safety.
\end{abstract}

\section{Background}

School bus accidents occurred frequently in china in recent years, which has become the main reason of the student injuries.

School Bus Safety Management Regulations and National Safety Standards of Special School Bus are first published by the State Council in 2012. They regulate the design, manufacture, use management, and safety performances of school bus to ensure student occupants' traffic safety[1].

Measures of Dongguan Municipality for The Administration of School Bus Safety (Draft for review) was published in July 2015. It specified that the maximum driving speed of the school bus occupied with students should be lower than $80 \mathrm{~km} / \mathrm{h}$ on the highway and lower than $60 \mathrm{~km} / \mathrm{h}$ on the other roads[2].

According to dynamic test methods in GB24406-2012[3], sled test of the school bus seat should be done at the speed of $30-32 \mathrm{~km} / \mathrm{h}$ to ensure the occupants being protected fully when the speed is lower than $30 \mathrm{~km} / \mathrm{h}$. However, the restraint system's protection for occupants is unknown at the speed of $30-50 \mathrm{~km} / \mathrm{h}$. This paper built a finite element simulation model of an existing school bus seat, and studied the occupant injury situation at different speeds.

\section{Occupant Restraint System Model}

3D model of the seat was imported into the HyperWorks software for geometric clean-up, meshing and other preprocessing[4]. Shell element type was selected for the seat framework, and solid element type for the seatback, cushion and other foam parts. In order to save computing time, the rear seats and the front seat cushion components were eliminated.

This school bus seat model was selected for middle school students. Hybird III 5th female dummy model was used to simulate the student according to the safety regulation GB24406-2012. The main components were the head, neck, thorax, abdomen, hip and limbs. All the components were given mass and moment of inertia according to the test dummy standard. The joints of human body parts were defined with the spherical hinge and rotary hinge unit, and were connected with non-linear torsion springs and damping unit to simulate the elasticity variation between the parts. The key components such as thorax and neck were set to be flexible, so as to simulate the injury of the human body during the collision[5]. 
Seat belts play an important role in the collision process. In this model, the belt was divided into two parts. The part in contact with human body was simulated by $2 \mathrm{D}$ thin shell elements, which can simulate the belt's sliding on the human body. 1D seatbelt elements were used to build the part not in contact with the human body and to simulate the relaxation of the seat belt during the collision process[6]. The school bus seat restraint system model is shown in Fig.1.Then the waveforms of different driving speeds were applied to the model, and the injury values of the occupant at different driving speeds were analyzed.

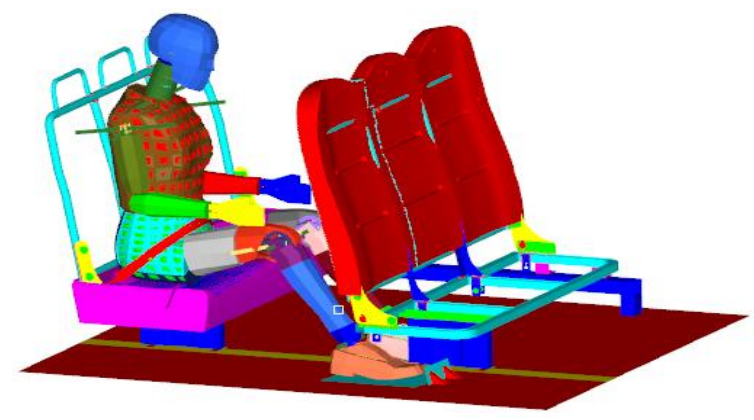

Fig.1. School bus seat restraint system model

\section{Simulation Results Analysis}

A series of occupant injury curves of the body parts were obtained by the simulation. According to GB24406-2012, the synthetic acceleration of the dummy head and the thorax, with the leg axial pressure curve, were processed with different frequency filters respectively. The comparison results are shown in Fig.2.

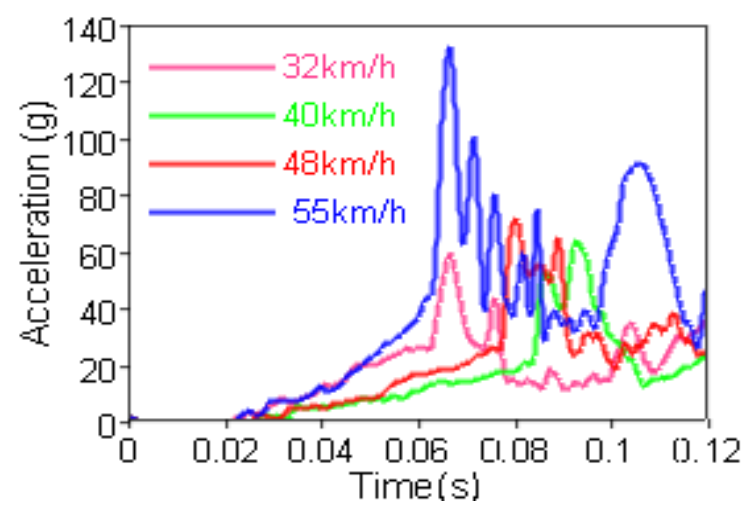

(a)Head acceleration curve

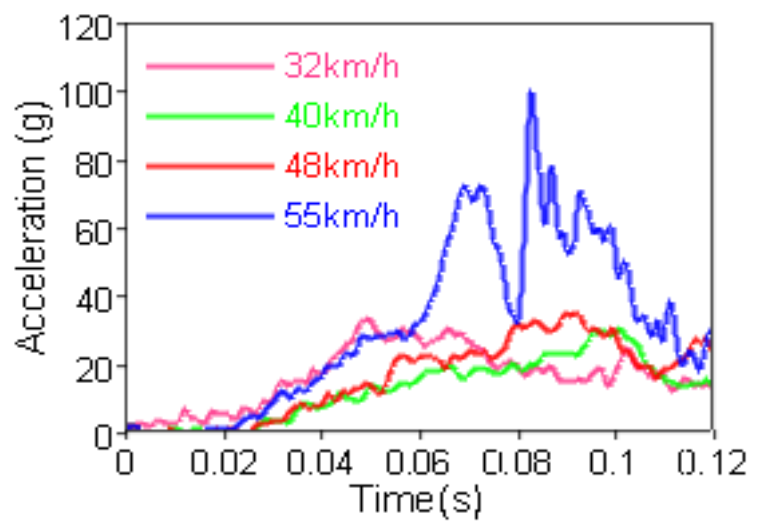

(b)Thorax acceleration curve

Fig.2. Occupant injury curves 


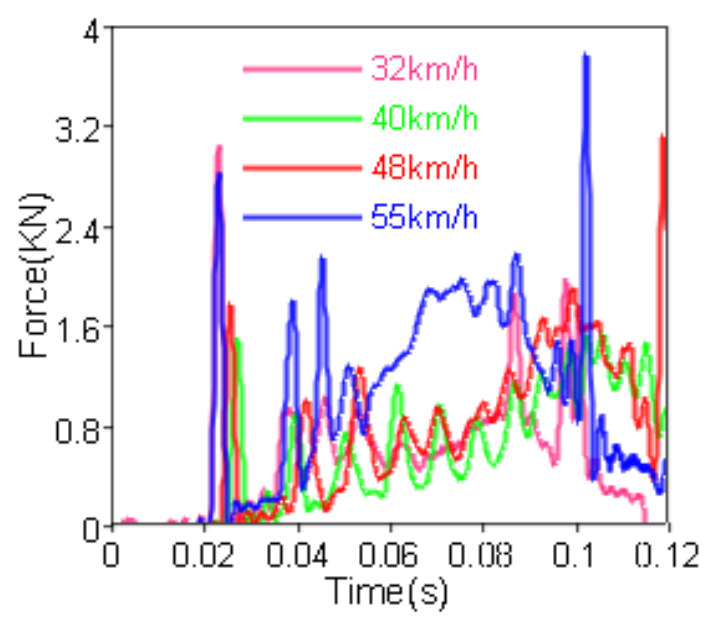

(c)Left leg axial pressure curve

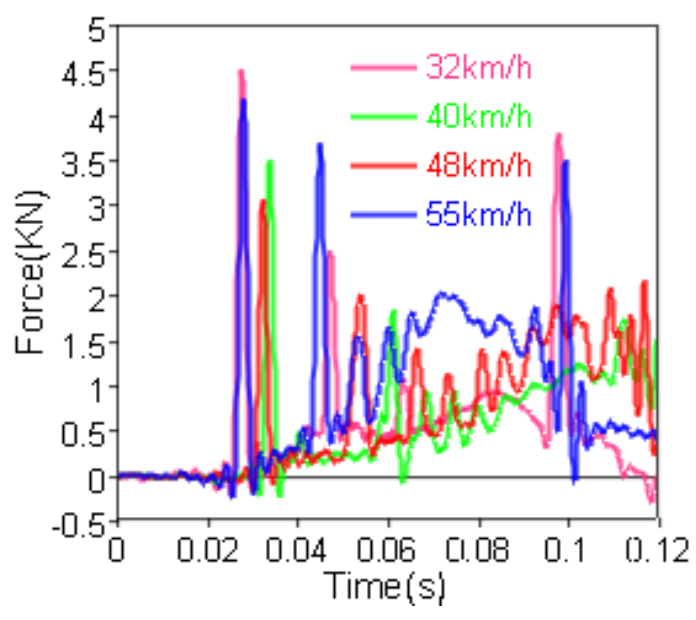

(d)Right leg axial pressure curve

Fig.2. Occupant injury curves

According to the results, the axial pressure of the thigh reaches the peak when the dummy's foot begins to contact with the baffle and the force of the baffle are transmitted from the foot to the leg. With the movement of the dummy's foot restricted by the baffle, the hip stops moving forward gradually, while the upper body continues to move forward. At the speed of $32 \mathrm{~km} / \mathrm{h}$, the dummy's head acceleration reaches the peak when the head impacts the seatback, while the thorax acceleration has the maximum value before the impact[1]. At the speed range of $40 \mathrm{~km} / \mathrm{h}$ to $55 \mathrm{~km} / \mathrm{h}$, both the head acceleration and the thorax acceleration reach the peak in the process of the head impacting the seatback, and the former occurs earlier than the latter.

The simulation curves were processed according to the requirements of GB24406-2012, and the injury values of the head, thorax and leg of the dummy at different driving speeds were calculated. The comparison results are shown in Table 1.

Table1. Comparison of occupant injury values at different driving speeds

\begin{tabular}{|l|l|l|l|l|}
\hline \multirow{2}{*}{ Injury index } & \multicolumn{4}{|c|}{ Driving speed (km/h) } \\
\cline { 2 - 5 } & 32 & 40 & 48 & 55 \\
\hline Head index HIC & 171.3 & 254.7 & 358.7 & 981 \\
\hline Thorax index a3ms (g) & 34.3 & 34.1 & 36.0 & 101.2 \\
\hline Axial pressure of leg FAC (KN) & 4.5 & 3.5 & 3.1 & 4.2 \\
\hline
\end{tabular}

It is shown that the head injury increases obviously with the increase of the driving speed. The maximum thorax $3 \mathrm{~ms}$ acceleration changes slightly when the driving speed ranges from $32 \mathrm{~km} / \mathrm{h}$ to 
$48 \mathrm{~km} / \mathrm{h}$. However, once the speed exceeds $48 \mathrm{~km} / \mathrm{h}$, thorax $3 \mathrm{~ms}$ acceleration value increases sharply. When the driving speed is at the range of $32 \mathrm{~km} / \mathrm{h}$ to $55 \mathrm{~km} / \mathrm{h}$, the energy of the collision process mainly releases at the stage when the head impacts the front seatback, therefore the leg injury keeps steady relatively.

\section{Conclusions}

By analyzing the occupant injury situation of a school bus seat at different driving speeds, we learn that:

1) In the low speed collision, the speed of school bus has little influence on the head injury of the occupant, but has great influence on the thorax and leg injuries of the occupant.

2) As the speed exceeds $48 \mathrm{~km} / \mathrm{h}$, it will cause more severe injury on the head and thorax, and the leg injury remains steady relatively.

3) Considering the usual driving speed of school bus, the range of $30 \mathrm{~km} / \mathrm{h}-50 \mathrm{~km} / \mathrm{h}$ would be relatively appropriate for the middle school student occupant's less injury in the traffic accident.

\section{Acknowledgements}

This study was financially supported by Science \& Technology Projects of Education Department of Fujian Province China, grant No. JA14240, Fujian Province Outstanding Youth Fund Scientific Research and Talent Cultivation Plan in Universities, grant No. JA14229, and Fujian Science \& Technology Project of China, grant No.2016H2003.

\section{References}

1. N. LYU, W.F. TAN, T. WANG, etc. Parameter optimization for school bus seat restraint system. Journal of Xiamen University of technology[J], 23(3):20-24 (2015)

2. Education Bureau of Dongguan Municipality. Measures of Dongguan Municipality for the administration of school bus safety (Draft for review)[S] (2015)

3. General Administration of Quality Supervision, Inspection and Quarantine of the People's Republic of China. GB24406-2012. The strength of student seat systems and their anchorages of special school bus[S]. Beijing: China Standards Press (2012)

4. Y.Z. HU, B.Q. ZENG, S.G. XIE. Automobile safety simulation and analysis based on LS-DYNA and Hyperworks[M]. Beijing: Tsinghua University Press: 18-46 (2011)

5. S.Q. HAN, C.L. WANG. Research on front crash safety of commercial vehicle[J]. Computer Aided Engineering, 15(s1):144-147 (2006)

6. S.K. Ye, C.F. Wu, D.F. Huang. Research and optimization for occupant injury on dynamic test for school bus seat[J]. Bus and Coach Technology and Research, 36(5):17-20 (2014) 